\title{
O TRABALHO DO PROFESSOR DE EDUCAÇÃO ESPECIAL ITINERANTE: UMA REVISÃO SISTEMÁTICA
}

\section{The work of the teacher of special education itinerant: a systematic review}

\author{
Osni Oliveira Noberto da Silva - UNEB/Brasil \\ Gildison Alves de Souza - UNEB/Brasil \\ Theresinha Guimarães Miranda - UFBA/Brasil \\ Miguel Angel Garcia Bordas - UFBA/Brasil
}

\begin{abstract}
RESUMO: O objetivo do presente estudo foi verificar por meio de revisão sistemática as produções acadêmicas acerca do trabalho itinerante do professor de Educação Especial. Nas buscas realizadas, foram encontradas 497 produções acadêmicas. Após a leitura dos títulos foram selecionados 36 estudos. Após serem analisados os resumos os estudos foram reduzidos para 13 e depois dos trabalhos lidos na íntegra chegamos ao total de 9 textos, sendo 8 Dissertações de Mestrado e 1 Tese de Doutorado. As nove produções acadêmicas escolhidas foram defendidas em seis Universidades, sendo cinco públicas e uma instituição privada e dois Centro Universitários, sendo duas instituições privadas. Em relação a distribuição regional das pesquisas temos cinco produzidos na região Sudeste (todos do estado de São Paulo), um na região Sul (estado do Rio Grande do Sul), um no Centro Oeste (no estado de Goiás) e um na região Norte (no estado do Pará). Não foi encontrado nenhum estudo produzido em Instituições de Ensino Superior da região Nordeste.
\end{abstract}

Palavras-chave: Educação Especial; Itinerante; Revisão sistemática.

ABSTRACT: The objective of the present study was to verify through a systematic review the academic productions about the itinerant work of the teacher of Special Education. In the searches, 497 academic productions were found. After reading the titles, 36 studies were selected. After the abstracts were analyzed the studies were reduced to 13 and after the works read in full we arrived at the total of 9 texts, being 8 Master Dissertations and 1 Doctoral Thesis. The nine academic productions chosen were defended in six Universities, five public and one private institution and two University Centers, two private institutions. In relation to the regional distribution of the researches we have five produced in the Southeast region (all of the state of São Paulo), one in the South region (Rio Grande do Sul state), one in the Center West (in the state of Goiás) and one in the North region (in the state of Pará). We did not find any study produced in Higher Education Institutions of the Northeast region.

Keywords: Special Education; Itinerant; Systematic review.

\section{INTRODUÇÃO}

O paradigma da inclusão, desenvolvido a partir de um movimento desenvolvido a partir dos anos 1980 do século XX na Europa e posteriormente na América do Norte, é

Educação, Psicologia e Interfaces, Volume 4, Número 2, p. 51-66, Abril/Junho, 2020.

ISSN: 2594-5343. DOI: 10.37444/issn-2594-5343.v4i2.294 
Osni Oliveira Noberto da Silva, Gildison Alves de Souza, Theresinha Guimarães Miranda \& Miguel Angel Garcia Bordas

hoje a base vigente nas propostas educacionais internacionais e brasileiras, principalmente após a Carta de Salamanca em 1994, que traz como princípio fundamental a ideia de que todos os alunos, com ou sem deficiência, devam aprender juntos no mesmo ambiente de convivência, sempre que for possível. E ainda:

Estas escolas devem reconhecer e satisfazer as necessidades diversas dos seus alunos, adaptando-se aos vários estilos e ritmos de aprendizagem, de modo a garantir um bom nível de educação para todos, através de currículos adequados, de uma boa organização escolar, de estratégias pedagógicas, de utilização de recursos e de uma cooperação com as respectivas comunidades. É preciso, portanto, um conjunto de apoios e de serviços para satisfazer o conjunto de necessidades especiais dentro da escola (UNESCO, 1994, p. 11-12).

As próprias urgências e emergências submersas desse movimento inclusivo se mostra importante principalmente quando se analisa os dados do Censo Escolar da Educação Básica que destaca um aumento exponencial no número de matrículas de alunos com deficiência nas escolas regulares do país, chegando a quase 900 mil no ano de 2017 (BRASIL, 2017).

Para Miranda (2006), para que se possa pensar numa educação que de fato seja realmente inclusiva é necessário que existam mudanças importantes com vistas a permitir um novo ambiente de aprendizagem dos alunos com deficiência e/ou necessidades educacionais especiais e assim, deixar para trás o que se compreende por uma educação tradicional que ainda persiste no país. E ainda segundo a autora:

(...) enquanto os alunos com deficiência física têm como critério para sua acessibilidade a existência de espaços físicos adaptados (rampas, corrimões, trincos de porta, banheiros, bebedouros, telefones públicos, etc.), em relação à deficiência visual, a acessibilidade depende de materiais como computadores com softwares adequados, impressoras Braille, etc. No concernente a surdez, o aluno deve ter direito a um intérprete em Língua Brasileira de sinais - LIBRAS- por exemplo (MIRANDA, 2006, p. 6).

Assim, a Educação Especial se tornou um elemento essencial nas políticas nos diversos documentos oficiais, como por exemplo a Resolução CNE/CEB no 02/01 que dispõe sobre a estabelece as Diretrizes brasileiras para a Educação Especial na Educação Básica. Este documento garante uma série de atribuições estruturais, materiais e formativas para profissionais da educação e instituições educacionais.

$\mathrm{O}$ artigo $8^{\circ}$, mais especificamente o item "c" do ponto IV diz que a garantia do serviço de apoio pedagógico que deve ser realizado para garantir a inclusão de alunos

Educação, Psicologia e Interfaces, Volume 4, Número 2, p. 51-66, Abril/Junho, 2020. 
com deficiência e/ou necessidades educacionais especiais, incluem "atuação de professores e outros profissionais itinerantes intra e interinstitucionalmente" (BRASIL, 2011).

Segundo Barros e Ramos (2013) o professor de Educação Especial que atua na itinerância é concebido como "um profissional cuja ações permeiam os diversos setores da escola, na direção de viabilização da inclusão" (pág. 4378). Ainda segundo os mesmos autores a atuação do professor itinerante implica em ações de apoio e acompanhamento da educação do aluno com deficiência, trabalhando em conjunto com o professor da sala comum, além de ser um agente de inclusão nas escolas da comunidade ao qual atua. $\mathrm{E}$ ainda:

(...) o professor itinerante é concebido como profissional que atende as peculiaridades da criança com deficiência, podendo atuar em todos os segmentos da escola como agente da inclusão. Nesse sentido, ele é o professor quando atua em conjunto com o professor de ensino regular na sala de aula ou SRM, é agente inclusivo quando atua fora destas sendo a sua atuação em dois lugares e com propostas diferentes, em uma prevalece o didático-pedagógico como prioridade para inclusão e na outra a inclusão como prioridade para assegurar o didáticopedagógico (BARROS; RAMOS, 2013, p. 4383).

Assim, observa-se a importância do professor itinerante para garantir que a proposta inclusiva seja materializada de forma eficiente no ambiente escolar. Por isso, este artigo tem como objetivo apresentar e analisar por meio de revisão sistemática as produções acadêmicas de Dissertações e Teses sobre o trabalho do professor de Educação Especial itinerante.

\section{METODOLOGIA}

A revisão sistemática pode ser compreendida como um tipo de revisão de literatura onde "os pesquisadores precisam das Revisão Sistemática (RS) para resumir os dados existentes, refinar hipóteses, estimar tamanhos de amostra e ajudar a definir agendas de trabalho futuro considerados como seus sujeitos" (MEDINA; PAILAQUILÉN, 2010, p. 7). De acordo com os mesmos autores, a revisão sistemática vem sendo cada vez mais utilizada e serve como uma opção relevante em contraponto aos tipos de revisão de literatura já consagradas.

Educação, Psicologia e Interfaces, Volume 4, Número 2, p. 51-66, Abril/Junho, 2020.

ISSN: 2594-5343. DOI: 10.37444/issn-2594-5343.v4i2.294 
Alguns passos são importantes para a produção de uma revisão sistemática, como a definição de um tema específico com a escolha dos critérios de inclusão, a seleção de algumas bases de dados para a busca dos textos que irão compor a revisão sistemática e consequentemente, a busca dos textos que serão analisados através do uso de uma ou mais palavras chave, a seleção dos textos relevantes para a revisão e sua análise (MUÑOZ et al. 2002). O momento de análise dos textos selecionados é um dos momentos mais importantes na revisão sistemática, como explicado por Muñoz et al. (2002, p.4):

A discussão deve ajudar o leitor a compreender as implicações da evidência apresentada em relação às decisões práticas. Os autores devem abordar, na discussão, aspectos como: limitações metodológicas e qualidade dos artigos incluídos na pesquisa, significância dos efeitos observados, consistência desses efeitos através dos diferentes estudos, clareza ou não da relação dose-resposta, existência de algum fator indireto que reforce a evidência, outras possíveis explanações para os efeitos observados e a aplicabilidade dos resultados. Podem, também, ser apresentadas algumas informações referentes ao custo-benefício das informações geradas.

O presente estudo é de natureza descritiva e com delineamentos tipo revisão sistemática, com o levantamento de trabalhos acadêmicos no Portal do Catálogo de Teses e Dissertações da CAPES, na Biblioteca Digital Brasileira de Teses e Dissertações e no Google Scholar, tendo como critérios de inclusão Dissertações de Mestrado e Teses de Doutorado defendidas nos últimos dez anos (2009 - 2019), em idioma português, utilizando como palavra chave "Itinerante". Nas buscas realizadas, foram encontradas 497 produções acadêmicas. Após a leitura dos títulos foram selecionados 36 estudos. Após serem analisados os resumos os estudos foram reduzidos para 13 e depois dos trabalhos lidos na íntegra chegamos ao total de 9 textos, sendo todos Dissertações de Mestrado.

\section{APRESENTAÇÃO E ANÁLISE DOS DADOS}

A amostra final para o estudo foi composta por nove produções acadêmicas, sendo oito Dissertações de Mestrado e uma Tese de Doutorado. O quadro 01 apresenta informações mais gerais sobre os referidos estudos.

Quadro 1 - Descrição dos trabalhos acadêmicos selecionados.

\begin{tabular}{|c|c|c|c|c|c|}
\hline Título & Autor & Ano & Tipo & Universidade & Cidade \\
\hline $\begin{array}{c}\text { A Educação Especial na } \\
\text { perspectiva da educação } \\
\text { inclusiva: ajustes e tensões }\end{array}$ & $\begin{array}{c}\text { Solange Santana } \\
\text { dos Santos } \\
\text { Fagliari }\end{array}$ & 2012 & Dissertação & $\begin{array}{c}\text { Universidade } \\
\text { de São Paulo }\end{array}$ & $\begin{array}{c}\text { São Paulo - } \\
\text { SP }\end{array}$ \\
\hline
\end{tabular}


O trabalho do professor de educação especial itinerante: uma revisão sistemática

\begin{tabular}{|c|c|c|c|c|c|}
\hline $\begin{array}{c}\text { entre a política federal e } \\
\text { municipal. }\end{array}$ & & & & & \\
\hline $\begin{array}{l}\text { Atendimento Educacional } \\
\text { Especializado: Desafios do } \\
\text { Professor Itinerante. }\end{array}$ & Regiane Franco & 2014 & Dissertação & $\begin{array}{c}\text { Centro } \\
\text { Universitário } \\
\text { Salesiano } \\
\end{array}$ & $\begin{array}{c}\text { Americana } \\
-\mathrm{SP}\end{array}$ \\
\hline $\begin{array}{l}\text { O ensino desenvolvido na } \\
\text { formação de professores } \\
\text { que atuam em sala de } \\
\text { recursos na rede municipal } \\
\text { de educação de } \\
\text { Imperatriz/MA. }\end{array}$ & $\begin{array}{l}\text { Ana Cláudia de } \\
\text { Sousa Alves }\end{array}$ & 2015 & Dissertação & $\begin{array}{c}\text { Centro } \\
\text { Universitário } \\
\text { Univates }\end{array}$ & $\begin{array}{c}\text { Lajeado - } \\
\text { RS }\end{array}$ \\
\hline $\begin{array}{l}\text { A atuação de uma equipe } \\
\text { multiprofissional no } \\
\text { apoio à educação } \\
\text { inclusiva. }\end{array}$ & $\begin{array}{l}\text { Márcia Altina } \\
\text { Bonfá da Silva }\end{array}$ & 2016 & Dissertação & $\begin{array}{l}\text { Universidade } \\
\text { Federal de } \\
\text { São Carlos }\end{array}$ & $\begin{array}{l}\text { São Carlos } \\
\text { - SP }\end{array}$ \\
\hline $\begin{array}{l}\text { Professor especializado da } \\
\text { sala de recursos } \\
\text { multifuncionais: um estudo } \\
\text { sobre a formação e práticas } \\
\text { pedagógicas }\end{array}$ & $\begin{array}{c}\text { Paula Regia } \\
\text { Bomfim Ferreira }\end{array}$ & 2016 & Dissertação & $\begin{array}{l}\text { Universidade } \\
\text { de Taubaté }\end{array}$ & $\begin{array}{l}\text { Taubaté - } \\
\text { SP }\end{array}$ \\
\hline $\begin{array}{l}\text { A trajetória do professor } \\
\text { itinerante na educação } \\
\text { inclusiva: ações e desafios } \\
\text { no contexto escolar da } \\
\text { localidade do Abade em } \\
\text { Curuçá-Pará }\end{array}$ & $\begin{array}{l}\text { Patrícia Milena } \\
\text { Silva Saldanha }\end{array}$ & 2017 & Dissertação & $\begin{array}{l}\text { Universidade } \\
\text { Federal do } \\
\text { Pará }\end{array}$ & Belém - PA \\
\hline $\begin{array}{c}\text { Ensino itinerante na } \\
\text { Educação Infantil: } \\
\text { investigando as práticas } \\
\text { docentes }\end{array}$ & $\begin{array}{l}\text { Lívia Maria } \\
\text { Ribeiro Leme } \\
\text { Anunciação }\end{array}$ & 2017 & Tese & $\begin{array}{l}\text { Universidade } \\
\text { Federal de } \\
\text { São Carlos }\end{array}$ & $\begin{array}{c}\text { São Carlos } \\
- \text { SP }\end{array}$ \\
\hline $\begin{array}{c}\text { Apoio Itinerante na } \\
\text { Educação Inclusiva em } \\
\text { uma escola da rede } \\
\text { estadual de ensino em } \\
\text { Buriti Alegre - GO. }\end{array}$ & $\begin{array}{c}\text { Luciene Guerra } \\
\text { dos Santos }\end{array}$ & 2018 & Dissertação & $\begin{array}{l}\text { Universidade } \\
\text { Federal de } \\
\text { Goiás }\end{array}$ & $\begin{array}{l}\text { Goiânia - } \\
\text { GO }\end{array}$ \\
\hline $\begin{array}{c}\text { O Atendimento } \\
\text { Educacional Especializado } \\
\text { nas escolas municipais de } \\
\text { educação infantil em São } \\
\text { Paulo. }\end{array}$ & $\begin{array}{l}\text { Maria Rachel } \\
\text { Compatangelo } \\
\text { Fernandes de Sá }\end{array}$ & 2018 & Dissertação & $\begin{array}{c}\text { Universidade } \\
\text { Presbiteriana } \\
\text { Mackenzie }\end{array}$ & $\begin{array}{c}\text { São Paulo - } \\
\text { SP }\end{array}$ \\
\hline
\end{tabular}

Fonte: Elaboração própria, 2019.

As nove produções acadêmicas escolhidas foram defendidas em seis Universidades, sendo cinco públicas e uma instituição privada e dois Centro Universitários, sendo duas instituições privadas. Em relação a distribuição regional das pesquisas temos seis produzidos na região Sudeste (todos do estado de São Paulo), um na região Sul (estado do Rio Grande do Sul), um no Centro Oeste (no estado de Goiás) e um na região Norte (no estado do Pará). Não foi encontrado nenhum estudo produzido em Instituições de Ensino Superior da região Nordeste.

Educação, Psicologia e Interfaces, Volume 4, Número 2, p. 51-66, Abril/Junho, 2020.

ISSN: 2594-5343. DOI: $10.37444 /$ issn-2594-5343.v4i2.294 
Osni Oliveira Noberto da Silva, Gildison Alves de Souza, Theresinha Guimarães Miranda \& Miguel Angel Garcia Bordas

A primeira investigação contida no quadro 1 trata-se de uma dissertação na qual Fagliari (2012) objetivou fazer a caracterização da construção da política de atendimento ao público-alvo da educação especial na cidade de São Bernardo do Campo, em São Paulo, tendo como recorte temporal do ano 1957 até 2008. Outro objetivo da autora foi o de analisar e descrever as ações praticadas na referida cidade entre 2009 e 2011, assim como as tensões, contradições, justificativas e desafios na implantação da política de inclusão escolar amparadas pelos documentos criados pelo Governo Federal com base na Política Nacional de Educação Especial na Perspectiva da Educação Inclusiva.

Fagliari (2012) descreve sua pesquisa como sendo qualitativa na qual, para chegar aos objetivos, optou pela realização de análise de documentos construídos pela Secretaria de Educação Especial, assim como a realização de entrevistas feitas com a equipe de orientação técnica e a gestora da Seção de Educação Especial de São Bernardo do Campo. Para analisar os dados, a autora selecionou documentos do Governo Federal e referencial teórico referente à Educação Inclusiva, Educação Especial e Políticas Públicas.

Como resultados, Fagliari (2012) identifica que ocorreram mudanças positivas na prestação de serviços voltados para pessoas com deficiência no que se refere ao AEE, tendo como ponto de tensão entre a política da cidade com a Federal o caráter substitutivo da educação ofertada para pessoas surdas, sendo que esses foram mantidos em escolas especiais. $\mathrm{O}$ autor conclui que os ajustes das políticas de São Bernardo do Campo com base nas diretrizes Federais, mesmo estando ocorrendo, mostraram-se como uma tarefa de grande complexidade, e reitera que até o final da pesquisa, não havia sido possível efetivar na cidade a implantação de todo o modelo estabelecido pelo Governo Federal.

A pesquisa de Franco (2014) também qualitativa, teve como objetivo compreender a prática cotidiana e o papel do professor itinerante de educação especial, bem como o entendimento que esse profissional tem acerca da escolarização de alunos com deficiência na escola regular; e conhecer de que forma é realizado o Atendimento Educacional Especializado em uma cidade situada no interior do estado de São Paulo. A autora não especifica em qual cidade a investigação foi realizada.

As escolas são descritas por Franco (2014) como tendo uma sala multifuncional cada onde ocorrem os atendimentos que são feitos pelos professores itinerantes que colaboraram com a pesquisa. Para obter os dados da pesquisa a autora analisou os Projetos Políticos Pedagógicos das duas escolas, além disso a autora observou dezessete sessões de atendimento de duas professoras, com três horas de duração cada, totalizando 
cinquenta e uma horas. Sequencialmente foi feita uma entrevista semiestruturada com respostas fechadas e abertas com duas professoras e treze professores que trabalham com Educação Especial da rede de ensino.

Como resultado o mesmo autor aponta que a legislação faz proposta de diversas mudanças, e que as escolas onde ocorreu a investigação mostraram avanços, mas, foi observado que a inclusão ainda não é real e completa, sendo considerada como um desconforto em uma geração que cresceu e foi educada em tempos no qual a inclusão não era discutida de forma ampla. É mostrado que os docentes dizem necessitar de apoio teórico e que desejam complementação na sua formação, o que mostra que tais necessidades não estão sendo atendidas. É reiterado que ainda há muito a ser feito, principalmente no que concerne a adequações ao que é posto em lei.

A dissertação de Alves (2015), de abordagem qualitativa, trata da formação de professores que trabalham nas salas de recursos multifuncionais na rede municipal de educação do município de Imperatriz no Maranhão. O estudo teve como objetivo geral realizar uma análise do desenvolvimento do ensino na formação de professores para atuarem nas salas de recursos oferecidas pelo Setor de Inclusão e Atenção à Diversidade (SIADI). A autora elencou como questão guia: de que forma o ensino ofertado na formação de docentes para trabalharem em sala de recursos, oferecida pelo SIADI, podem contribuir para a inclusão de estudantes com deficiência na rede municipal de ensino?

Alves (2015) teve como sujeitos da pesquisa três professoras que atuam em sala de recursos. A autora adotou como metodologia a pesquisa de campo, composta por observação. Além disso foi realizada uma pesquisa documental na qual a autora buscou registros referentes aos anos de 2010 a 2013 no SIADI para verificar quais as formações que foram realizadas. A coleta de informações com os sujeitos da pesquisa deu-se por meio de entrevista semiestruturada gravada e transcrita.

A partir das análises realizadas, Alves (2015) identificou algumas problemáticas mencionadas pelas professoras e que são particulares no exercício da profissão em questão, como, por exemplo, a falta de articulação entre docentes da classe regular e os da sala de recursos; e a ausência de acompanhamento advindo da equipe de formação. Porém, as falas registradas nas entrevistas comprovam que o ensino desenvolvido nas formações oferecidas pelo SIADI tem contribuído para o aprimoramento das práticas das 
professoras que atuam na sala de recursos, e que ela colaborou, também, para a efetivação da inclusão dos estudantes com deficiência matriculados na rede de ensino regular.

A investigação de Silva (2016), trata-se de uma pesquisa qualitativa que teve como objetivo geral, realizar a descrição e análise das ações de uma equipe multiprofissional, identificando, em conjunto com os profissionais da equipe, táticas para aprimorá-la. A autora teve como colaboradores da pesquisa: três psicólogas, o mesmo número de fonoaudiólogas e uma pedagoga que trabalhavam em cinco escolas da rede municipal de ensino de um município do interior de São Paulo. A autora não menciona qual é o município.

Para chegar ao objetivo geral o autor utilizou a pesquisa colaborativa como metodologia, dividindo a investigação em quatro etapas. A primeira foi a execução de um estudo documental para assim poder caracterizar o contexto no qual os participantes atuam. A segunda foi a realização de entrevistas individualmente intencionando descrever e analisar o trabalho realizado pelos sujeitos. A terceira foi a reflexão acerca do serviço da equipe com intervenções feitas em grupos focais no qual foram identificadas estratégias para aprimorar os atendimentos. A quarta etapa foi a análise da proposta de organização do trabalho elaborada pela equipe a partir da intervenção feita na etapa anterior.

O processamento dos dados obtidos foi feito à luz da análise de conteúdo temática. Silva (2016) organizou os resultados de acordo com as etapas da investigação. Os resultados da primeira etapa tornaram possível a contextualização do histórico de elaboração do serviço da equipe. Os da segunda etapa tornaram possível identificar dois modelos de serviços, o clínico e o educacional, além disso a autora concluiu que existe uma demanda escolar pelos especialistas componentes do grupo, entretanto, havia a expectativa de realização de serviços clínicos.

Os resultados da terceira etapa da pesquisa de Silva (2016) tornaram evidentes as dificuldades inerentes a práticas coletivas e colaborativas da equipe na instituição de ensino, sendo necessária a definição de papeis e a reflexão acerca da cultura da escola como elementos influenciadores das mudanças. A última etapa mostrou que a aplicação da pesquisa colaborativa causou reflexos no projeto final da equipe. Assim, o autor conclui que os serviços prestados por uma equipe multiprofissional podem contribuir com a efetivação da inclusão nas escolas, desde que haja uma filosofia única de trabalho e a 
formação continuada dos sujeitos. Ademais, embora o trabalho multiprofissional não seja comum no Brasil, ele tem se mostrado como sendo de grande eficiência.

Ferreira (2016) realizou uma pesquisa qualitativa que teve como objetivo de sua investigar a formação e as práticas pedagógicas que são desenvolvidas por docentes especializados do Programa Integra-Ativa (PIA), da rede de ensino municipal de Taubaté em São Paulo e que trabalham em salas de recursos multifuncionais. Como metodologia Ferreira (2016) optou por uma pesquisa de campo que teve como sujeitos: uma coordenadora do PIA e quatorze docentes especializadas que atuam na sala de recursos. Para coletar os dados, a autora fez uso da entrevista semiestruturada e análise documental.

Os dados encontrados por Ferreira (2016) foram submetidos à análise de conteúdo e foram dispostos em quatro categorias: colaboradores da pesquisa; formação e trajeto profissional na educação especial; AEE: organização e funcionamento na perspectiva das docentes; e pratica pedagógica no meio escolar.

A autora teve como resultados a percepção de que há a necessidade de realização de uma reorganização do PIA para que seja feito o direcionamento do AEE inserido em uma abordagem pedagógica, uma vez que a formação das professoras está imbuída por um viés médico, percebido no diagnóstico das necessidades educativas dos estudantes com deficiência, e, por conseguinte, nas práticas pedagógicas. Esses fatores fizeram com que Ferreira (2016) apontasse a formação continuada desses profissionais como algo imprescindível, considerando que, a formação imbuída de reflexão crítica acerca da escola e sua organização, assim como a sobre os direcionamentos necessários no AEE, podem contribuir para a redefinição das práticas pedagógicas exercidas pelas professoras especialistas.

Em sua dissertação, de método qualitativo, Saldanha (2017) teve como objetivo geral efetuar a análise do trajeto e das ações do professor itinerante em seu dia-a-dia profissional para promover a educação inclusiva no município de Curuçá no Pará, mais especificamente na localidade do Abade. A autora teve três objetivos específicos: identificar o percurso e ações realizados pelo professor itinerante em seu cotidiano afim de efetivar a educação inclusiva na referida localidade; analisar as dificuldades enfrentadas pelo professor itinerante para a realização de seu trabalho; e identificar os desafios enfrentados por esse profissional que atua no Abade em Curuçá. A pesquisadora teve como sujeito da pesquisa uma professora que atente de três escolas diferentes. 
A metodologia utilizada por Saldanha (2017) foi a exploratória onde o levantamento de dados foi feita por meio de entrevistas, observação e diário de campo, relatórios e fotografias. As conclusões foram que, mesmo a professora entrevistada sendo uma das pioneiras do AEE no local onde a investigação foi realizada, ainda há a necessidade de aprimoramento nas suas metodologias de trabalho, sendo preciso também a melhoria da relação entre a professora itinerante com os profissionais que atuam nas salas de aula regular no que diz respeito à avaliação e frequência dos alunos.

O autor aponta que mesmo não sendo o ideal, contratar uma professora itinerante foi a alternativa encontrada para que fosse possível, de alguma forma, atender as demandas existentes nas escolas de Curuçá. A pesquisadora conclui que existe a imprescindibilidade de criação de espaços específicos em duas das escolas para que a professora itinerante efetue suas intervenções, nessas escolas não existe sala de recursos, sendo necessário que salas onde as aulas regulares acontecem precisem ser cedidas para acontecer o AEE. Outro ponto mencionado é que a professora itinerante tem que transportar seu próprio material, mas mesmo assim a referida profissional se mostra incentivada profissionalmente afirmando ser impulsionada pelas dificuldades a buscar mais conhecimento para compreender a complexidade das diversas características dos estudantes atendidos por ela.

A investigação de Anunciação (2017) trata-se de uma Tese de método qualitativo cujo objetivo geral foi investigar, em conjunto com professores que trabalham no ensino itinerante, de que forma são efetuadas as práticas docentes direcionadas a crianças com síndrome de Down. Para isso, a pesquisadora delimitou três objetivos específicos: identificar a relação entre o aluno da educação infantil com síndrome de Down e o professor itinerante, assim como as práticas pedagógicas na oferta do ensino itinerante nessa fase da educação básica; investigar de que maneira o ensino itinerante acontece na Educação Infantil; e delinear de que forma as práticas educacionais acontecem no contexto escolar.

Anunciação (2017) apresenta a metodologia de sua tese como sendo um estudo de caso de caráter exploratório e descritivo. O lócus da investigação foi uma cidade descrita como sendo de médio porte localizada no interior de São Paulo, na Rede Municipal de Ensino na educação infantil. Os sujeitos da pesquisa foram cinco professores que trabalham no ensino itinerante em escolas de Educação Infantil, e o mesmo número de alunos com síndrome de Down. 
O trabalho do professor de educação especial itinerante: uma revisão sistemática

Os dados da tese de Anunciação (2017) foram coletados com entrevistas semiestruturadas feitas individualmente. Sequencialmente as entrevistas, foi feita uma observação e registro em diário da prática dos docentes com as crianças com síndrome de Down. Como resultados, a autora aponta que somente uma das professoras não mencionou pontos negativos na atuação itinerante. As outras docentes relatam que o número de escolas atendidas e a inexistência de vínculo empregatício com as escolas são pontos que dificultam o estabelecimento do ensino itinerante.

A pesquisadora menciona ainda que uma das características do referido serviço é a necessidade de realização de um trabalho conjunto com o professor do ensino regular, porém, existem obstáculos nesse processo, como, por exemplo, a falta de formação do docente que atua no ensino regular no que concerne ao trabalho com alunos com deficiência, assim como a falta de contato antecipado entre os profissionais para que ocorra o planejamento.

É trazido ainda como resultados que apesar de o ensino itinerante ocorrer em atividades conjuntas com o professor do ensino regular, existem práticas individualizadas. Anunciação (2017) relata que os sujeitos da pesquisa não atendem apenas crianças com deficiência, mas também com distúrbios comportamentais e trabalham de acordo com a demanda. É mencionado como barreira o fato de que os recursos materiais que devem ser usados para a adaptação de atividades são escassos, assim como a disponibilização de verbas para a aquisição de materiais. Por fim, foi possível observar contínua mediação do profissional itinerante nas práticas pedagógicas, sem que houvesse relação com o docente do ensino regular.

Em sua dissertação, Santos (2018) discute a função do professor de apoio itinerante em uma escola da Educação Básica da rede estadual de ensino em Buriti Alegre, município localizado no estado de Goiás. Trata-se de uma pesquisa qualitativa cujo objetivo geral foi verificar se nos atendimentos de alunos com deficiência, a intervenção do professor itinerante colabora na escolarização, partindo do planejamento, aplicação e avaliação das atividades em três componentes curriculares: matemática, língua portuguesa e língua estrangeira, podendo ser inglês ou espanhol.

Entre os objetivos específicos a autora destaca que pretende apresentar o projeto de criação grupo de estudos à direção da escola e sensibilizar os professore itinerantes a formarem o grupo. Outro dos objetivos específicos é identificar as dificuldades que os

Educação, Psicologia e Interfaces, Volume 4, Número 2, p. 51-66, Abril/Junho, 2020.

ISSN: 2594-5343. DOI: 10.37444/issn-2594-5343.v4i2.294 
Osni Oliveira Noberto da Silva, Gildison Alves de Souza, Theresinha Guimarães Miranda \& Miguel Angel Garcia Bordas

professores itinerantes enfrentam; verificar os avanços e problemas da itinerância na escola; verificar os obstáculos, possibilidades e avanços na relação entre o professor itinerante, docente de classe regular e alunos; e, por fim, planejar, desenvolver e avaliar propostas didático-pedagógicas para ajudar o profissional de apoio itinerante em suas intervenções.

Para chegar aos objetivos da dissertação, Santos (2018) optou pela pesquisa-ação como metodologia. A autora coletou dados a partir da realização de um grupo de estudos envolvendo dois professores de apoio itinerante, um que atua com AEE e a própria autora que se intitula como professora de poio itinerante e regente. Além disso, foi feita uma entrevista semiestruturada e revisão bibliográfica.

Santos (2018) destaca como resultados que a despeito das barreiras existentes num atendimento fragmentado, existe a possibilidade de chegar a soluções eficientes a partir da parceria entre os agentes e a formação continuada. É enfatizado também que, por conta da insegurança dos professores de classe regular, a responsabilidade pela escolarização de alunos com deficiência é transferida, quase que totalmente, para os professores especialistas, acontecendo por muitas vezes o que foi identificado pela pesquisadora como sendo segregação uma vez que não há a devida interação entre todos os alunos regulares.

O último trabalho do quadro 1 é uma dissertação com abordagem qualitativa onde Sá (2018) elenca como objetivo geral analisar o AEE proposto na Política de Educação Especial de São Paulo, nas escolas municipais de educação infantil. E teve como objetivos específicos: verificar de que forma é organizado o AEE nas escolas de educação infantil em uma Diretoria Regional de Educação na zona oeste de São Paulo; e identificar o olhar do professor que atua em escolas municipais de educação infantil frente ao AEE realizado nessa etapa de ensino.

Sá (2018) utilizou do método transversal de pesquisa de caráter descritivoanalítico. A coleta de dados foi feita em três momentos, o primeiro foi a entrevista semiestruturada realizada com dois coordenadores que atuam em um Centro de Formação e Acompanhamento à Inclusão e uma professora de AEE; o segundo foi a aplicação de questionários via internet com docentes que trabalham com crianças em AEE em escolas municipais de educação infantil, e, por último, a identificação da necessidade de alunos atendidos nas referidas escolas.

Educação, Psicologia e Interfaces, Volume 4, Número 2, p. 51-66, Abril/Junho, 2020. 
O trabalho do professor de educação especial itinerante: uma revisão sistemática

Após a análise dos dados, Sá (2018) notou que embora a nova política de Educação Especial pôr à disposição três distintas modalidades de AEE - itinerante, colaborativo e contraturno - nas escolas pesquisadas, a modalidade praticada é majoritariamente a itinerante, na qual o docente da classe regular realiza o AEE. Ademais, foi constatado imensa dificuldade por parte do professor itinerante de efetuar suas intervenções de forma colaborativa com o docente da turma regular, de forma a auxiliálo a elaborar estratégias e recursos pedagógicos que possam aprimorar o processo de ensino-aprendizagem.

\section{CONSIDERAÇÕES FINAIS}

Aqui retomamos o objetivo do texto que foi apresentar e analisar por meio de revisão sistemática as produções acadêmicas de Dissertações e Teses sobre o trabalho do professor de Educação Especial itinerante.

Os dados demonstram uma grande concentração de estudos produzidos em instituições do estado de São Paulo. Ainda mais grave o fato de que nenhuma Dissertação ou Tese do tema proposto nesta revisão sistemática foi encontrada.

Assim, é necessário que mais estudos sejam produzidos, principalmente nas Instituições do Ensino Superior da região Nordeste, ainda mais levando a relevância do tema dos professores de Educação Especial itinerantes.

Principalmente porque o tema apresentado neste texto se mostrou extremamente atual e relevante, não só por conta das garantias legais do trabalho do professor de Educação Especial que atua como itinerante, escrito nos documentos oficiais inclusive, mas também por conta do momento atual de intensos ataques ao ensino público e a própria educação do país.

\section{REFERÊNCIAS BIBLIGRÁFICAS}

ALVES, Ana Cláudia de Sousa. O ensino desenvolvido na formação de professores que atuam em sala de recursos na rede municipal de educação de Imperatriz/MA. 106 f. Dissertação (Mestrado em Ensino) Centro Universitário Univates, Lajeado - RS, 2015. Disponível em: https://www.univates.br/bdu/handle/10737/1139 Acesso em: jan. 2019.

ANUNCIAÇÃO, Lívia Maria Ribeiro Leme. Ensino itinerante na Educação Infantil: investigando as práticas docentes. $166 \mathrm{f}$. Tese (Doutorado em Educação Especial),

Educação, Psicologia e Interfaces, Volume 4, Número 2, p. 51-66, Abril/Junho, 2020.

ISSN: 2594-5343. DOI: 10.37444/issn-2594-5343.v4i2.294 
Universidade Federal de São Carlos, São Carlos - SP, 2017. Disponível em: https://repositorio.ufscar.br/handle/ufscar/8899 Acesso em: jan. 2019.

BARROS, Mércia Ramos de; RAMOS, Kátia Maria da Cruz. Lugar do professor itinerante no processo de inclusão de alunos com deficiência nas séries iniciais do Ensino Fundamental. In: LOPES, Amélia; CAVALCANTE, Maria Auxiliadora da Silva; OLIVEIRA, Dalila Andrade; HYPÓLITO, Álvaro Moreira (Orgs.) Trabalho Docente e Formação: Políticas, Práticas e Investigação: Pontes para a mudança. Anais do II Encontro Luso Brasileiro, Portugal. Porto: Centro de Investigação e Intervenção Educativas, 2013.

BRASIL. Censo Escolar. Instituto Nacional de Estudos e Pesquisas Educacionais Anísio Teixeira. Brasília: Inep, 2017.

BRASIL. Resolução CNE/CEB n ${ }^{\circ}$ 02/01. Institui Diretrizes nacionais para a Educação Especial na Educação Básica. Brasília: MEC, 2001.

FAGLIARI, Solange Santana dos Santos. A Educação Especial na perspectiva da educação inclusiva: ajustes e tensões entre a política federal e a municipal. $267 \mathrm{f}$. Dissertação (Mestrado em Educação), Universidade de São Paulo, São Paulo - SP, 2012. Disponível em: https://www.teses.usp.br/teses/disponiveis/48/48134/tde28092012-135842/pt-br.php Acesso em: agos. de 2019.

FERREIRA, Paula Regia Bomfim. Professor especializado da sala de recursos multifuncionais: um estudo sobre a formação e práticas pedagógicas. $179 \mathrm{f}$. Dissertação (Mestrado em Desenvolvimento Humano) Universidade de Taubaté. Taubaté - SP, 2016. Disponível em: https://mpemdh.unitau.br/wpcontent/uploads/2014/dissertacoes/mdh/Paula-Regia-Bomfim-Ferreira.pdf Acesso em: agos. de 2019.

FRANCO, Regiane. Atendimento educacional especializado: desafios do professor itinerante. 2014. 84 f. Dissertação (Mestrado em Educação), Centro Universitário Salesiano de São Paulo. Americana - SP. Disponível em: https://unisal.br/wpcontent/uploads/2015/08/26.02.14Disserta\%C3\%A7\%C3\%A3o-Regiane-Franco.pdf Acesso em: agos. de 2019.

URRA MEDINA, Eugenia; BARRIA PAILAQUILEN, René Mauricio. A revisão sistemática e a sua relação com a prática baseada na evidência em saúde. Rev. LatinoAm. Enfermagem, Ribeirão Preto, v. 18, n. 4, p. 824-831, Ago. 2010 . Disponível em: <http://www.scielo.br/scielo.php?script=sci_arttext\&pid=S0104$11692010000400023 \& \operatorname{lng}=$ en\&nrm=iso >. Acesso em 02 jan. 2019. https://doi.org/10.1590/S0104-11692010000400023.

MIRANDA. Theresinha Guimarães. A inclusão de pessoas com deficiência na universidade. In: Anais do seminário de pesquisa em educação especial, Vitória: UFES, 2006.

MUÑOZ, Susana Inés Segura; TAKAYANAGUI, Angela Maria Magosso; SANTOS, Claúdia Benedita dos; SANCHEZ-SWEATMAN, Otto. Revisão sistemática de literatura e metanálise: noções básicas sobre seu desenho, interpretação e aplicação na 
área da saúde. In: Simpósio Brasileiro de Comunicação em Enfermagem, SIBRACEN, Ribeirão Preto (SP). Anais... Escola de Enfermagem de Ribeirão Preto da USP, 2002.

SÁ. Maria Rachel Compatangelo Fernandes de. O Atendimento Educacional Especializado nas escolas municipais de educação infantil em São Paulo. $83 \mathrm{f}$. Dissertação (Mestrado em Distúrbios do Desenvolvimento). Universidade Presbiteriana Mackenzie. São Paulo - SP, 2018. Disponível em:

http://tede.mackenzie.br/jspui/handle/tede/3666 Acesso em: agos. de 2019.

SALDANHA. Patrícia Milena Silva. A trajetória do professor itinerante na educação inclusiva: ações e desafios no contexto escolar da localidade do abade em Curuçá-Pará. 129 f. Dissertação (Mestrado em Linguagens e Saberes na Amazônia). Universidade Federal do Pará. Belém - PA, 2017.

SANTOS, Luciene Guerra dos. Apoio Itinerante na Educação Inclusiva em uma escola da rede estadual de ensino em Buriti Alegre - GO. 143 f. Dissertação (Mestrado em Ensino da Educação Básica), Universidade Federal de Goiás. Goiânia GO, 2018. Disponível em: https://repositorio.bc.ufg.br/tede/handle/tede/8682 Acesso em: agos. de 2019.

SILVA, Márcia Altina Bonfá da. A atuação de uma equipe multiprofissional no apoio à educação inclusiva. 182 f. Dissertação (Mestrado em Educação Especial), Universidade Federal de São Carlos, São Carlos - SP, 2016. Disponível em: https://repositorio.ufscar.br/bitstream/handle/ufscar/7545/DissMABS.pdf? sequence $=1 \&$ isAllowed=y Acesso em: agos. de 2019.

UNESCO. Declaração de Salamanca: Sobre princípios, políticas e práticas na área as necessidades educativas especiais. Salamanca - Espanha, 1994.

\section{Credenciais da/os autora/es}

SILVA, Osni Oliveira Noberto da. Mestre e Doutorando em Educação pela Universidade Federal da Bahia (UFBA). Professor do Departamento de Ciências Humanas, Campus IV, da Universidade do Estado da Bahia (UNEB). Líder do Grupo de estudos, pesquisa e extensão em Educação Especial e Educação Física adaptada (GEPEFA) e integrante do Grupo de estudos sobre Educação Inclusiva e Necessidades Educacionais Especiais (GEINE). E-mail: osni_edfisica@yahoo.com.br

SOUZA, Gildison Alves de. Licenciado em Educação Física e Mestre em Educação e Contemporaneidade, ambos pela Universidade do Estado da Bahia (UNEB). Integrante do Grupo de estudos, pesquisa e extensão em Educação Especial e Educação Física adaptada (GEPEFA).

E-mail: gildson.alvescg@gmail.com

MIRANDA, Theresinha Guimarães. Doutora em Educação pela Universidade de São Paulo, com pós-doutorado pela Umeå University, Suécia. Professora do Programa de Pós-

Educação, Psicologia e Interfaces, Volume 4, Número 2, p. 51-66, Abril/Junho, 2020. 
graduação em Educação da Universidade Federal da Bahia (UFBA). Integrante do Grupo de estudos sobre Educação Inclusiva e Necessidades Educacionais Especiais (GEINE). E-mail: tmiranda@ufba.br

BORDAS, Miguel Angel Garcia. Doutor em Filosofia pela Universidad Complutense de Madrid, com pós-doutorado pela Universitat Autònoma de Barcelona, Espanha. Professor do Programa de Pós-graduação em Educação da Universidade Federal da Bahia (UFBA). Integrante do Grupo de estudos sobre Educação Inclusiva e Necessidades Educacionais Especiais (GEINE).

E-mail: magbordas@gmail.com

Endereço para correspondência: Avenida Senhor dos Passos, 64. Bairro Vicente Ferreira. Capim Grosso-BA, CEP: 44695-000. E-mail: osni_edfisica@yahoo.com.br

Como citar este artigo (Formato ABNT): SILVA, Osni Oliveira Noberto, et al. O trabalho do professor de educação especial itinerante: uma revisão sistemática. Educação, Psicologia e Interfaces, v. 4, n. 2, p. 51-66, 2020. Doi: 10.37444/issn-25945343.v4i2.294

Recebido: 07/09/2019.

Aceito: 03/02/2020. 